\title{
Identification of Bordetella pertussis in nasopharyngeal swabs by PCR amplification of a region of the adenylate cyclase gene
}

\author{
ELAINE DOUGLAS, J. G. COOTE $\dagger$, R. PARTON and W. McPHEAT* \\ Department of Microbiology, University of Glasgow, Glasgow G12 $8 Q Q$ and *Division of Bacteriology, National \\ Institute for Biological Standards and Control, South Mimms, Hertfordshire EN6 $30 \mathrm{G}$
}

\begin{abstract}
Summary. The polymerase chain reaction (PCR) was used to amplify a 522-bp region of the adenylate cyclase toxin (cyaA) gene of Bordetella pertussis. As few as $100 \mathrm{cfu}$ from a suspension of $B$. pertussis could be detected by this procedure when the amplified PCR product was detected by ethidium bromide staining of agarose gels. However, simulated clinical specimens, prepared from swabs impregnated with known numbers of $B$. pertussis cells, only yielded a positive reaction with $\geqslant 10^{4} \mathrm{cfu}$. Hybridisation of a Southern blot of the PCR products from the swab samples with a $c y a$-specific probe gave a positive reaction with as few as $8 \mathrm{cfu}$, but the hybridisation signal was uniformly weak with fewer than $10^{4} \mathrm{cfu}$. Nevertheless, three of 13 nasopharyngeal swabs, taken from suspected clinically defined cases of whooping cough and stored frozen for up to 18 months, gave a positive PCR reaction.
\end{abstract}

\section{Introduction}

At present, the bacteriological confirmation of Bordetella pertussis in cases of whooping cough is often unsuccessful for a variety of reasons. These include the slow growth and fastidious nature of the organism, variability in swabbing techniques, time taken in transport of specimens to the laboratory, and the fact that the infection is being cleared by host defences as the typical disease symptoms appear. Isolation rates may be as low as $20 \%$ from suspected cases. ${ }^{1}$ The alternative method of serological diagnosis can also be unreliable, with an efficacy ranging from 21 to $67 \%$ in one report. ${ }^{2}$

DNA probe technology is particularly suited to the detection of an organism like $B$. pertussis, which grows poorly on laboratory media. There is a further advantage in that, because growth is not required, it should be possible to collect specimens and store them frozen for long periods. B. pertussis produces, as one of its virulence factors, an adenylate cyclase toxin which is able to penetrate mammalian cells and raise the internal cyclic AMP concentration. ${ }^{3}$ The genetic determinant for the toxin has been cloned and sequenced. ${ }^{4.5}$ We report here on the use of primerdirected enzymic amplification of DNA (polymerase chain reaction or $\mathrm{PCR}^{6}$ ) to amplify a region of the

Received 1 May 1992: revised version accepted 17 July 1992.

+ Correspondence should be sent to Dr J. G. Coote.

* Present address: Biotechnology Department, ICI Pharmaceuticals, Alderly Park, Cheshire SK10 4TG. adenylate cyclase gene, and on the suitability of the technique for detection of bordetellae in clinical swabs.

\section{Materials and methods}

\section{Bacterial strains}

The following strains of Bordetella spp. were used and have been described. ${ }^{7,8} \quad B$. pertussis $18-323$ (NCTC 10739); B. parapertussis NCTC 10520; B. bronchiseptica 276; and B. avium P-4084. Bacillus subtilis NCTC 3610, Neisseria meningitidis 4076 and Streptococcus pneumoniae (NIBSC laboratory stock strains) were also used.

\section{Media and culture conditions}

Strains of Bordetella spp. were grown at $37^{\circ} \mathrm{C}$ in a moist atmosphere on Bordet-Gengou (BG) medium (Gibco-BRL) containing defibrinated horse blood (Gibco-BRL) $20 \% \mathrm{v} / \mathrm{v}$. Other organisms were grown at $37^{\circ} \mathrm{C}$ on Nutrient Agar (Oxoid), Tryptone Soya Agar (Oxoid) or Brain Heart Infusion Agar (Oxoid).

\section{Sample preparation}

Bacteria were washed from agar plates with sterile distilled water and routinely adjusted to 10 optical units with a standard opacity rod. ${ }^{9}$ This opacity is equivalent to $c .2 \times 10^{9} \mathrm{cfu} / \mathrm{ml}$ in the case of $B$. pertussis, and this was confirmed by viable counting. Portions $(100 \mu \mathrm{l})$ of serial dilutions were heated for 
$10 \mathrm{~min}$ at $100^{\circ} \mathrm{C} ; 5 \mu \mathrm{l}$ of each boiled sample was then used in the PCR assay. Fine tip cotton-wool or alginate swabs (Medical Wire and Equipment, Corsham) for use in the simulation experiments were impregnated with $10 \mu \mathrm{l}$ of a cell suspension of $B$. pertussis. Each swab was then immersed in $50 \mu \mathrm{l}$ of distilled water, agitated thoroughly, and centrifuged for $10 \mathrm{~min}$ at $12000 \mathrm{rpm}$ in a Heraeus microfuge. The swab was then removed to a small microfuge tube with a hole in the bottom, and then re-centrifuged inside the larger tube containing the first wash. A further $50 \mu \mathrm{l}$ of distilled water was then added to the swab and the centrifugation step repeated. The combined eluate $(c .100 \mu \mathrm{l})$ was then heated to $100^{\circ} \mathrm{C}$, as above, and $20 \mu \mathrm{l}$ was used in the PCR assay. Nasopharyngeal cotton-wool swab specimens (Transwab; Medical Wire and Equipment) were collected from patients presenting with suspected, clinically-defined whooping cough (paroxysmal cough lasting for at least 2 weeks that was associated with a typical whoop, vomiting or apnoeic episodes). The initial, direct, hybridisation experiments were performed on samples supplied by Dr M. Thomas (St George's Hospital Medical School, London) that were culture-positive for $B$. pertussis, confirmed by agglutination with $B$. pertussis-specific antisera. Later samples for PCR analysis were supplied from various sources within the UK between February and August 1989. Such samples had been used for culture and were sent in the original charcoal or blood agar transport medium; they were then stored frozen for up to 18 months until processed as above.

\section{PCR amplification}

This was performed over 25 cycles, involving denaturation at $94^{\circ} \mathrm{C}(1 \mathrm{~min})$, primer annealing at $55^{\circ} \mathrm{C}$ $(2 \mathrm{~min})$, and primer extension at $72^{\circ} \mathrm{C}(3 \mathrm{~min})$, with a Techne PHC-1 automatic thermal cycler. Each 50- $\mu$ 1

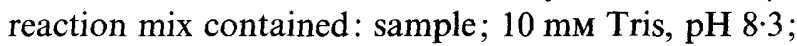
$50 \mathrm{mM} \mathrm{KCl} ; 1.5 \mathrm{mM} \mathrm{MgCl}_{2}$; gelatin $100 \mu \mathrm{g} / \mathrm{ml} ; 200 \mu \mathrm{M}$ of each deoxyribonucleotide; $1 \mu \mathrm{M}$ of each primer; and $2.5 \mathrm{U}$ of Taq polymerase (Perkin-Elmer-Cetus). At the end of the reaction, $20 \mu \mathrm{l}$ of the mixture was analysed by electrophoresis on an agarose (type II-A; Sigma) $1.5 \%$ gel. ${ }^{4}$ The 20 -bp primers spanned bases $1-20$ and 503-522, starting from the ATG translational start codon, of the cyaA structural gene. ${ }^{5}$ The primers were synthesised by the phosphite triester method with an AB1 381A automatic DNA synthesiser (Applied Biosystems) by Dr V. Math, Biochemistry Department, Glasgow University.

\section{DNA techniques}

Preparation of plasmid DNA, restriction digests, ligations, transformations, agarose gel electrophoresis, Southern blotting on to Hybond-N nylon membranes (Amersham), and autoradiography were as described previously. ${ }^{4,8}$ To obtain radiolabelled molecular size standards, $\lambda$ DNA was digested with HindIII and labelled with ${ }^{32} \mathrm{P}-\mathrm{dATP}$ as described by Downing et $a l .^{10}$ For probe preparation, a 200-bp ApaLI/BstEII fragment internal to the DNA fragment amplified by PCR (spanning bases 185-385 of the cyaA gene) was cloned into pSP64. ${ }^{11}$ The purified plasmid DNA was digested with BamHI and EcoRI, and a resulting 211bp fragment was excised from an agarose gel and radiolabelled to high specific activity by the method of Feinberg and Vogelstein. ${ }^{12}$ Hybridisations were performed at $42^{\circ} \mathrm{C}$ in the presence of formamide $50 \%$. After $24 \mathrm{~h}$, filters were washed twice in $1 \times \operatorname{SSC}(0.15 \mathrm{M}$ $\mathrm{NaCl}, 0.015 \mathrm{M} \mathrm{Na}$ citrate, $\mathrm{pH} 7.0$ ), SDS $0.1 \%$ at $68^{\circ} \mathrm{C}$ for $2 \mathrm{~h}$ before autoradiography. For dot-blot analysis, $100-\mu 1$ portions of bacterial cell suspensions were denatured by heating at $50^{\circ} \mathrm{C}$ for $10 \mathrm{~min}$ in $100 \mu \mathrm{l} 0.4 \mathrm{~N}$ $\mathrm{NaOH}$. The samples were then loaded into the wells of a multi-well manifold apparatus (Schleicher and Schuell) fitted with nylon membrane. Each well was

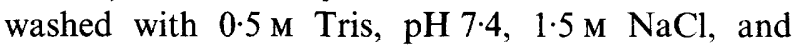
hybridisation was performed as above.

\section{Results}

\section{Direct hybridisation}

Preliminary work assessed the efficacy of direct hybridisation to $B$. pertussis DNA immobilised on nylon membranes. A 211-bp DNA fragment, internal to the $c y a A$ fragment amplified in later experiments by PCR, was radiolabelled and used as a probe against DNA passed through a dot-blot apparatus following release by boiling from dilutions of a $B$. pertussis cell suspension. The detection limit of this procedure, by visual inspection of the autoradiograph, was estimated to be $5 \times 10^{4} \mathrm{cfu}$. Attempts to recover sufficient cell material from six clinical swabs (taken from cultureconfirmed cases of whooping cough) to give a positive reaction by the dot-blot assay were unsuccessful.

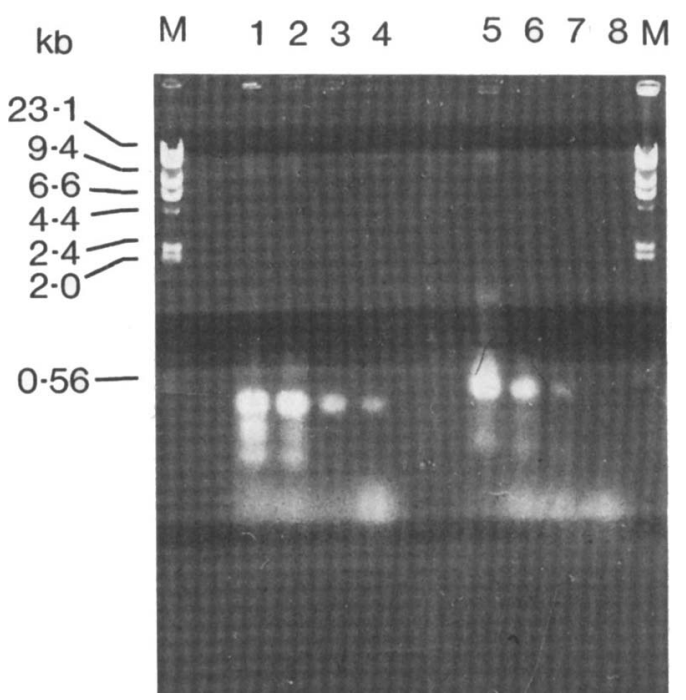

Fig. 1. Sensitivity of detection of $B$. pertussis by PCR. Dilutions of a standard cell suspension were assayed, subjected to agarose gel electrophoresis, and DNA was visualised by staining with ethidium bromide. Results are from two separate experiments. Numbers of cfu used for assay were: lane $1,10^{7} ; 2,10^{6} ; 3,10^{5} ; 4,10^{4} ; 5,10^{4} ; 6$, $10^{3} ; 7,10^{2} ; 8$, negative control. $\mathbf{M}$, fragment sizes $(\mathrm{kb})$ of HindIIIdigested $\lambda$ DNA. 


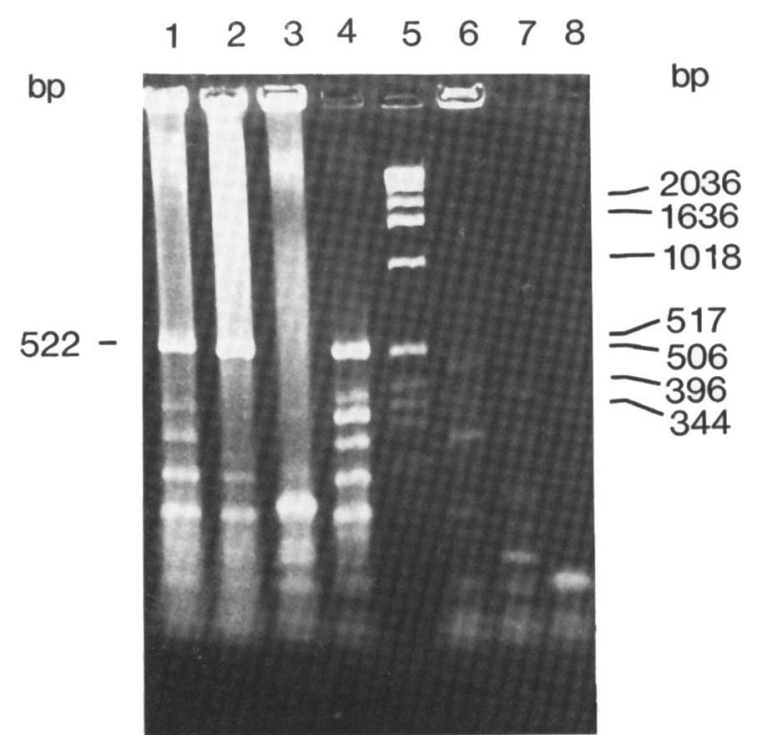

Fig. 2. Specificity of detection of Bordetella spp. by PCR. DNA from $10^{8} \mathrm{cfu}$ of each organism was processed as in fig. 1 . The 522-bp cla $\mathrm{A}$ gene fragment is indicated. Lane 1, B. pertussis; 2 , B. bronchiseptica: 3. B. arium; 4, B. parapertussis; 5, 1-kb DNA ladder (Gibco-BRL) with relevant fragment size (bp) shown on right; 6. Bac. subtilis; 7 , $N$. meningitidis; $\mathbf{8}, S$. pneumoniae.

\section{PCR amplification}

The problem of low numbers of bacteria on nasopharyngeal swabs, and hence small amounts of target DNA, was addressed by means of PCR amplification. The sensitivity of the procedure was assessed by PCR assays on boiled cell suspensions. When a $B$. pertussis cell suspension containing $2 \times 10^{9} \mathrm{cfu} / \mathrm{ml}$ was serially diluted and subjected to PCR, amplification of a 522bp fragment, visible on ethidium bromide-stained agarose gels, was obtained from $\geqslant 100 \mathrm{cfu}$ (fig. 1). The cloned cyaA gene has been shown previously to

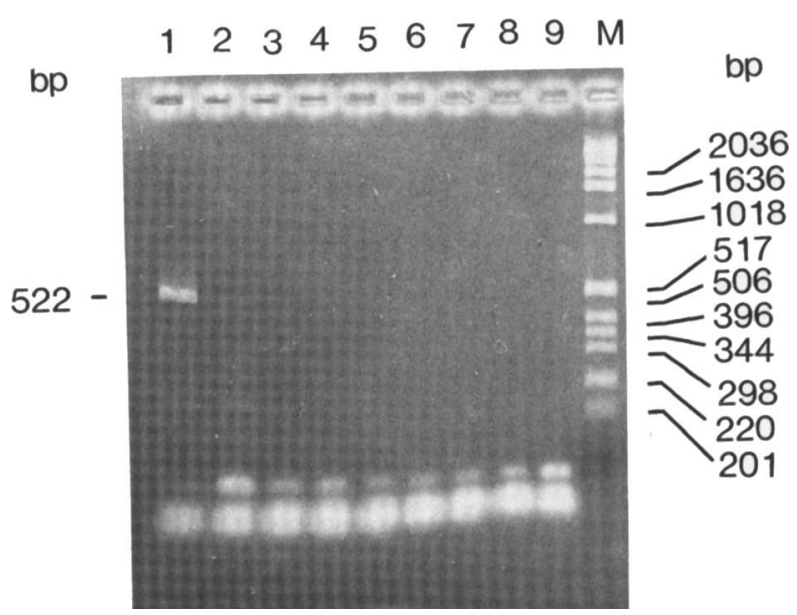

Fig. 4. PCR assay of nasopharyngeal swab samples taken from patients with suspected, clinically defined, whooping cough. Lanes 1-8 are clinical specimens and lane 9 is a negative control. Lane $\mathbf{M}$ contains a 1-kb DNA ladder (Gibco-BRL), with the relevant sizes (bp) shown on the right.

hybridise in Southern blots to DNA from B. pertussis, $B$. parapertussis and $B$. bronchiseptica, but not to DNA from $B$. avium. ${ }^{4}$ This pattern was also exhibited with the PCR assay. The cyaA primers amplified a 522bp fragment from all the bordetellae except $B$. avium, but no such amplification product was obtained with DNA from Bac. subtilis, $N$. meningitidis or $S$, pneumoniae (fig. 2). High cell numbers were deliberately used in each assay, which may be the reason for the presence of several low molecular size, non-specific amplification products visible in each lane.

Samples for routine diagnosis of $B$. pertussis in the UK are taken by nasopharyngeal swabs, so it was important to assess the sensitivity of detection of bacteria eluted from such swabs. Simulated swab specimens were prepared by applying known numbers a

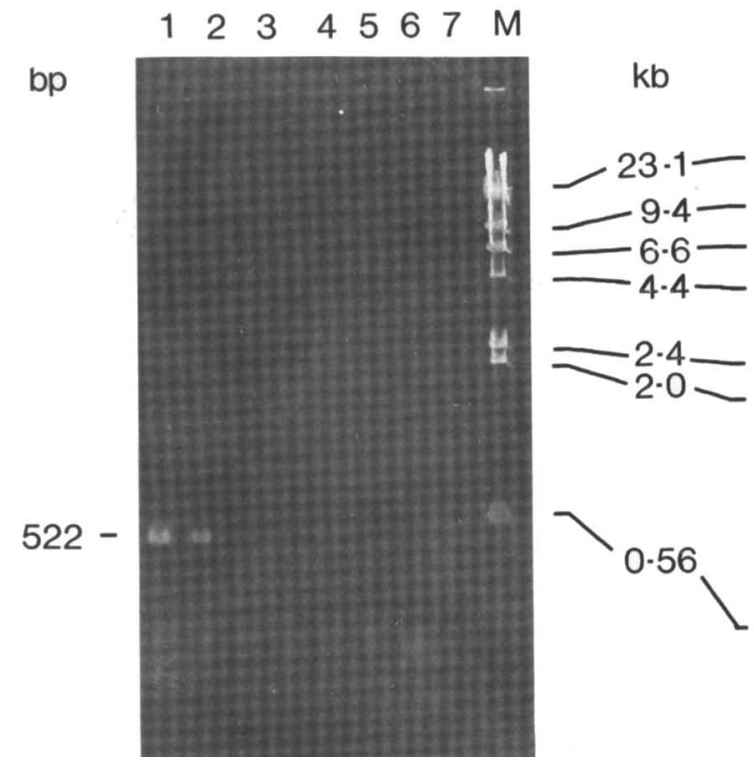

b $\begin{array}{llllllll}M & 1 & 2 & 3 & 4 & 5 & 6 & 7\end{array}$

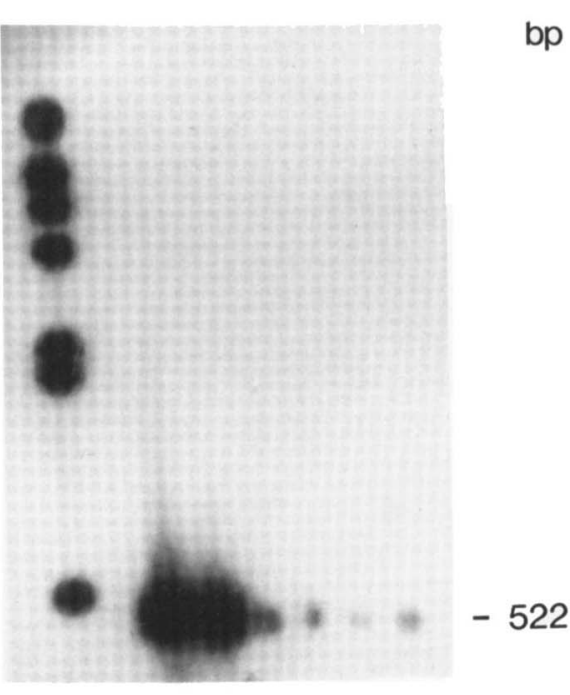

Fig. 3. PCR assay of simulated swab specimens. Dilutions of a standard $B$. pertussis cell suspension were applied to swabs, material eluted and assayed. The numbers of cfu used for each assay were: lane $1,8 \times 10^{5} ; 2.8 \times 10^{4} ; 3,8 \times 10^{3} ; 4,8 \times 10^{2} ; 5,80 ; 6,8 ; 7$, negative control Lane $\mathbf{M}$ contains radiolabelled fragments (sizes shown in $\mathrm{kb}$ ) of HindIII-digested $\lambda$ DNA. (a) Amplified DNA visualised by ethidium bromide staining. (b) Autoradiograph of DNA transferred to a nylon membrane and hybridised with a radiolabelled probe internal to the amplified fragment. 
of $B$. pertussis cells to either cotton-wool or alginate swabs. Cells were then eluted and the eluates were used for PCR assays. No amplified product was detected when alginate swabs were used, but the 522-bp fragment was amplified and visible on agarose gels from cotton-wool swabs loaded with $8 \times 10^{4} \mathrm{cfu}$ (fig. $3 \mathrm{a}$ ), an appreciably lower level of detection than that obtained following simple dilution of a cell suspension when $100 \mathrm{cfu}$ were detected. Hybridisation of a Southern blot of this gel, with the probe internal to the amplified fragment, revealed that as few as $8 \mathrm{cfu}$ applied to the swab gave a positive hybridisation reaction following PCR assay (fig. 3b). However, the signal was uniformly weak from those cell dilutions which did not give a positive reaction by ethidium bromide staining. This pattern of a non-linear response of the PCR reaction with respect to cell numbers applied to the swabs was detected reproducibly, and indicated that the PCR reaction was unable to proceed to completion in simulated samples prepared from low numbers of bacteria.

PCR amplification of the 522-bp cyaA gene fragment was also used in an attempt to detect Bordetella spp. from swabs taken from suspected, clinically defined, cases of whooping cough. In an analysis of eight samples (fig. 4), one sample gave a positive reaction (lane 1), while in an analysis of five further samples, two were positive (data not shown).

\section{Discussion}

Previous reports ${ }^{13,14}$ have shown that the PCR can detect low numbers of $B$. pertussis cells in nasopharyngeal aspirates with primers that amplify regions of the pertussis toxin S1 subunit gene or a repetitive DNA sequence, both of which are species-specific. Houard et al. ${ }^{13}$ were able to detect $B$. pertussis in five of 10 nasal aspirates taken from suspected cases of whooping cough, while Glare et al. ${ }^{14}$ reported that, from a total of 332 samples, 63 of 66 culture-confirmed aspirates were positive by the PCR, as were 33 culturenegative specimens. In the present study, with nasopharyngeal swabs taken from patients with suspected whooping cough, three of 13 swabs gave a positive PCR reaction. This was encouraging since the swabs had been frozen and stored for a long period before testing. The swabs had been supplied after subculture

\section{References}

1. Onorato IM, Wassilak SGF. Laboratory diagnosis of pertussis: the state of the art. Pediatr Infect Dis J 1987; 6: 145-151.

2. Lawrence AJ, Paton JC. Efficacy of enzyme-linked immunosorbent assay for rapid diagnosis of Bordetella pertussis infection. J Clin Microbiol 1987; 25 : 2102-2104.

3. Hanski E. Invasive adenylate cyclase toxin of Bordetella pertussis. Trends Biochem Sci 1989; 14: 459-463.

4. Brownlie RM, Coote JG, Parton R, Schultz JE, Rogel A, Hanski E. Cloning of the adenylate cyclase genetic determinant of Bordetella pertussis and its expression in for $B$. pertussis diagnosis, but the culture response was not reported to us, except in three instances which were reported as culture-negative. One of the three latter swabs gave a positive PCR reaction, which emphasised the value of the PCR reaction for detection of $B$. pertussis in samples which present as culture-negative. However, the work with simulated swab specimens suggested that it was difficult to obtain a positive PCR reaction with low numbers of bacteria, either because of inhibitory material eluted from the swabs or because of a poor yield of bacteria in the eluates, a feature which may have been exacerbated by prolonged storage. As the work coincided with an inter-epidemic period, it was not possible to repeat the PCR assays on fresh specimens to assess the effect of prolonged storage on the efficacy of the PCR method.

This work extends previous reports by showing that PCR can be used to detect $B$. pertussis on clinical swabs as well as in aspirates. However, it was clear that insufficient cells, and hence DNA, were available on a clinical swab to ensure the detection of $B$. pertussis directly by hybridisation, at least with the $c y a$-specific probe. This may be caused by inefficient removal of cells from the swab or sequestering of DNA by the swab material. Amplification of target DNA by PCR increased the sensitivity of detection, but more work is needed to demonstrate that the procedure used in conjunction with clinical swab specimens offers greater reliability than the standard culture and serological tests. The PCR reaction may, however, be unsuitable for routine use in a diagnostic laboratory, since it is very sensitive to cross-contamination resulting in falsepositive results. ${ }^{15,16}$ The method may be more useful in vaccine efficacy trials where specimens can be collected and stored before assay. The alternative to use of the PCR for increasing the sensitivity of a gene probe assay is to amplify the signal-generating capacity of the system rather than the target DNA. ${ }^{17}$ The use of probes specific for $B$. pertussis, such as those used by Houard et al.$^{13}$ and Glare et al. ${ }^{14}$ in combination with a probe specific to other human pathogenic bordetellae, such as that used in this report, will be useful for identifying the presence of $B$. parapertussis or $B$. bronchiseptica in clinical specimens.

This work was supported by a grant from the Medical Research Council and equipment made available by the Wood Boyd Medical Research Fund of Glasgow University. We thank Dr M. Thomas and the various hospital sources who supplied us with swab specimens.
Escherichia coli and B. pertussis. Microb Pathog 1988; 4 : 335-344.

5. Glaser P, Ladant D, Sezer O, Pichot F, Ullmann A, Danchin A. The calmodulin-sensitive adenylate cyclase of Bordetella pertussis: cloning and expression in Escherichia coli. Mol Microbiol 1988; 2: 19-30.

6. Saiki RK, Gelfand DH, Stoffel S et al. Primer-directed enzymatic amplification of DNA with a thermostable DNA polymerase. Science 1988; 239: 487-491.

7. Parton R. Differentiation of phase I and variant strains of Bordetella pertussis on Congo red media. J Med Microbiol 1988; 26: 301-306. 
8. McGillivray DM, Coote JG, Parton R. Cloning of the virulence regulatory (vir) locus of Bordetella pertussis and its expression in B. bronchiseptica. FEMS Microbiol Lett 1989; 65: $333-338$.

9. Perkins FT, Sheffield FW, Outschoorn AS, Helmsley DA. An international collaborative study on the measurement of the opacity of bacterial suspensions. J Biol Stand 1973; 1: $1-10$.

10. Downing RG, Duggleby CJ. Villems R, Broda P. An endonuclease cleavage map of the plasmid pWWO-8, a derivative of the TOL plasmid of Pseudomonas putida mt-2. Mol Gen Genet 1979; 168: 97-99.

11. Melton DA, Krieg PA, Rebagliati MR, Maniatis T, Zinn K, Green MR. Efficient in vitro synthesis of biologically active RNA and RNA hybridization probes from plasmids containing a bacteriophage SP6 promoter. Nucleic Acids Res $1984 ; 12$ : 7035-7056.
12. Feinberg AP, Vogelstein B. A technique for radiolabelling DNA restriction endonuclease fragments to high specific activity-Addendum. Anal Biochem 1984; 137: 266-267.

13. Houard S, Hackel C, Herzog A, Bollen A. Specific identification of Bordetella pertussis by the polymerase chain reaction. Res Microbiol 1989; 140: 477-487.

14. Glare EM, Paton JC, Premier RR, Lawrence AJ, Nisbet IT. Analysis of a repetitive DNA sequence from Bordetella pertussis and its application to the diagnosis of pertussis using the polymerase chain reaction. J Clin Microbiol 1990; 28: 1982-1987.

15. Kwok S, Higuchi R. Avoiding false positives with PCR. Nature 1989; 339: 237-238

16. Kitchin PA, Szotyori Z, Fromholc C, Almond N. Avoidance of false positives. Nature 1990; 344: 201.

17. Fahrlander PD. Amplifying DNA probe signals: a "christmas tree" approach. Bio/Tech 1988; 6: 1165-1168. 